\title{
Corrigendum: Microbe Profile: Pseudomonas aeruginosa: opportunistic pathogen and lab rat
}

\author{
Stephen P. Diggle* and Marvin Whiteley* \\ Microbiology 2020;166:30-33, doi: 10.1099/mic.0.000860
}

In the published version of this article, there was an error in the second sentence of the section 'Properties'.

The sentence 'It is a facultative aerobe that grows via aerobic respiration and anaerobic respiration with nitrate as the terminal electron acceptor.' should have read 'It is a facultative anaerobe that grows via aerobic respiration and anaerobic respiration with nitrate as the terminal electron acceptor'.

The authors apologise for any inconvenience caused. 